\title{
METABOLITE PROFILING OF CORE OIL PALM TRUNK (COPT) SAP: THE EFFECTS OF DIFFERENT STORAGE DURATIONS, CONDITIONS AND TEMPERATURES
}

\section{MARHAINI MOSTAPHA*; NOORHASMIERA ABU JAHAR*; SARANI ZAKARIA*; WAN MOHD AIZAT**; KAMALRUL AZLAN AZIZAN** and SHARIFAH NABIHAH SYED JAAFAR*}

\begin{abstract}
In Malaysia, core oil palm trunk (COPT) is one of the biomass that has been left underutilised due to its low properties. Nonetheless, metabolites contained in COPT sap may provide an alternative natural resources for bio-chemicals and pharmaceuticals. Metabolites such as sugars are easily affected by analytical factors during storage. In this study, the changes of metabolite contents in COPT sap stored at different storage durations, conditions and temperatures were observed by using gas chromatography-mass spectrometry (GC-MS) based metabolomics approach. The changes of metabolite contents, particularly sugars and organic acids were analysed using univariate and multivariate statistical analysis. The separation trends observed in the principal component analysis (PCA) score plot was greatly influenced by storage temperatures. However, two-way analysis of variance (ANOVA) revealed that the majority of significant metabolites $(P<0.05)$ was strongly influenced by storage durations. The metabolite increased significantly when COPT was stored as raw rather than sap. The highest sugar concentrations in $\mathrm{COPT}$ were found at $10^{\circ} \mathrm{C}$ for one month (R-10-1M). Furthermore, the organic acids increased significantly when stored at $4^{\circ} \mathrm{C}$ for one month (R-4-1M). The results indicated different storage durations, conditions and temperatures led to variation in the COPT sap metabolite content.
\end{abstract}

\section{Keywords: GC-MS, metabolomics, principal component analysis, free sugars, organic acid.}

Date received: 20 March 2017; Sent for revision: 22 May 2017; Received in final form: 3 December 2017 ; Accepted: 26 January 2018.

\section{INTRODUCTION}

Palm oil is a highly valuable commodity with values reaching RM $2780 \mathrm{t}^{-1}$ of crude palm oil, RM $2886 \mathrm{t}^{-1}$ for palm olein and RM $2711 \mathrm{t}^{-1}$ for palm kernel oil (MPOC, 2017). According to the Malaysian Palm Oil Board (MPOB), oil palm are replanted every 25

\footnotetext{
* Bioresources and Biorefinery Laboratory,

Faculty of Science and Technology,

Universiti Kebangsaan Malaysia,

43600 Bangi, Selangor, Malaysia.

** Metabolomics Research Laboratory,

Institute of Systems Biology (INBIOSIS)

Universiti Kebangsaan Malaysia, 43600 Bangi,

Selangor, Malaysia.

E-mail: kamalrulazlan@ukm.edu.my
}

years, which contributed up to 8.2 million tonnes of oil palm trunk (OPT) per year (MPOB, 2016). OPT is one of the most underutilised biomass from the palm oil industry, which usually would be chopped and left to decompose naturally at the plantation (Abdullah and Sulaiman, 2013). As a strategy to promote sustainability, the usage of OPT intovaluable materials such as compressed wood (Sulaiman et al., 2012), bioethanol (Yamada et al., 2010), lactic acid (Chooklin et al., 2011), 5-hydroxymethyl furfural (Mostapha et al., 2016) and methyl levuinate (Jahar et al., 2017) are of great interest. Furthermore, the utilisation of OPT into such products will encourage a proper oil palm waste management as well as making it profitable to the industry. This will open 
up more opportunities and benefits, particularly to rural regions and supports the usage of the oil palm biomass for a sustainable future.

Metabolomics is the global analysis approach to study metabolites in a biological system. The approach relies heavily on analytical tools and multivariate data analysis to obtain and process metabolite profile. Gas chromatography-mass spectrometry (GC-MS) is an important analytical tool in metabolomics and often used to detect key small molecules such as sugars, amino acids and organic acids (Warth et al., 2015). GC-MS is relatively economical, easy to use and offer good sensitivity in detecting metabolites. Metabolites are usually known as small molecules that have important and various functions in a biological process. Metabolites are highly diverse, easily affected by environmental perturbation and their changes are correlated to a specific phenotypic characteristic (Field and Lake, 2011). Therefore, metabolite analysis via metabolomics can generate important information to comprehend phenotype of a biological system in response to the ever-changing surroundings.

Previous research showed that several metabolomics studies have been conducted on various parts of oil palm including leaves (Vargas et al., 2016), fruits (Neoh et al., 2013) and mesocarp (Bourgis et al., 2011; Teh et al., 2013). To our knowledge, there is no comprehensive metabolomics studies done on OPT sap, particularly on OPT sap stored at different conditions. Ahmad et al. (2010) reported that OPT contains roughly $23.3 \%$ lignin, $72.12 \%$ holocellulose and $2.3 \%$ ash. The sap from OPT is rich with free sugars such as glucose (25.29 $\left.\mathrm{g}_{\text {litre }}{ }^{-1}\right)$, fructose $\left(6.28 \mathrm{~g} \mathrm{litre}^{-1}\right)$ and sucrose $(2.44 \mathrm{~g}$ litre $^{-1}$ ) (Shamsir et al., 2017). Particularly, these free sugars increased as they are stored at 30-60 days after logging (Yamada et al., 2010). Additionally, organic acids such as citric acid $\left(380.6 \mathrm{\mu g} \mathrm{g}^{-1}\right)$, malic acid $\left(371.8 \mu \mathrm{g} \mathrm{g}^{-1}\right)$ and maleic acid $\left(119.1 \mu \mathrm{g} \mathrm{g}^{-1}\right)$ were dominantly found in sap (Kosugi et al., 2010).

In this study, GC-MS-based metabolomics analysis was conducted to identify and quantify the metabolite profiles of core oil palm trunk (COPT) sap. The aim of the study is to investigate the effects of storage conditions (sap and raw), temperatures $\left(4^{\circ} \mathrm{C}\right.$ and $10^{\circ} \mathrm{C}$ ) and durations (one week and one month) of COPT sap. The univariate and multivariate statistical analysis (MVA) were then used to evaluate the relationship between these storage parameters and their influence on the metabolite contents.

\section{MATERIALS AND METHODS}

\section{Plant Materials and Chemicals}

The middle (height position) parts of COPT, approximately 29 years old oil palm (Elaeis guineensis), a Tenera variety (hybrid between the Dura and Pisifera) were obtained from Leong Brothers Earthworks Construction, Kluang, Johor, Malaysia (N143'39.3", E10341'38.4"). Chloroform (99.8\%), ribitol $(99 \%)$, pyridine $(99.8 \%)$, methoxyamine hydrochloride (MeOX) $(98 \%)$ and N-Methyl-N(trimethylsilyl) trifluoroacetamide (MSTFA) (99.5\%) were purchased from Sigma-Aldrich, USA. The HPLC-grade methanol $(99.9 \%)$ was purchased from Merck, USA. All chemicals were used without further purification.

\section{Samples Preparation}

The COPT was stored in two conditions as sap and raw under different storage durations and temperatures (Appendix 1). Briefly, sap was extracted from COPT by using a laboratory press scale machine. The collected COPT sap was then stored at $4^{\circ} \mathrm{C}(\mathrm{S}-4)$ and $10^{\circ} \mathrm{C}(\mathrm{S}-10)$ for one week (1W) and one month $(1 \mathrm{M})$. After storage durations completed, the COPT sap was then subjected to freeze drying for derivatisation and GC-MS analysis. These samples were later named as S-4-1W, S-10-1W, S-4$1 \mathrm{M}$ and S-10-1M. On the other hand, raw COPT was obtained and wrapped with paper and stored at $4{ }^{\circ} \mathrm{C}$ $(\mathrm{R}-4)$ and $10^{\circ} \mathrm{C}(\mathrm{R}-10)$ for one week (1W) and one month (1M). Sap from the stored raw COPT was then extracted by using the laboratory press scale machine and subjected to freeze drying prior to derivatisation and GC-MS analysis. These samples were later named as R-4-1W, R-10-1W, R-4-1M and $\mathrm{R}-10-1 \mathrm{M}$. The fresh COPT sap was used as a control (C-0) sample.

\section{Total Metabolite Extraction}

Approximately $20 \mathrm{mg}$ of freeze dried COPT sap samples were extracted by using $1.0 \mathrm{ml}$ mixture of chloroform:methanol:water (1:1:1). The liquid mixtures were then shaken for $30 \mathrm{~s}$ by using a vortex mixer and rotated for $20 \mathrm{~min}$ at $200 \mathrm{rpm}$. The extracted samples were stored at $-80^{\circ} \mathrm{C}$ overnight. Then, the samples were thawed and centrifuged at $4^{\circ} \mathrm{C}, 10000 \mathrm{rpm}$ for $10 \mathrm{~min}$ to separate the two resulting fractions. The top fraction was transferred into a new $1.5 \mathrm{ml}$ microcentrifuge tube and ribitol (20 $\mu \mathrm{l}, 0.18 \mathrm{mg} \mathrm{ml}^{-1}$ ) was added as an internal standard (Neoh et al., 2013). The extracts were then dried using nitrogen gas to remove the excess solvent.

\section{Derivatisation Procedure}

Derivatisation method was carried out as described by Ruitz-Matute et al. (2011) with minor modifications. Briefly, $40.0 \mu \mathrm{l}$ pyridine containing MeOX was added to the dried extract samples. The mixture was shaken for $30 \mathrm{~s}$ by using a vortex mixer 
and then it was incubated. Later, $40 \mu$ l of MSTFA was added into the mixture and re-shaken for $30 \mathrm{~s}$ and re-incubated. The reactions were incubated at $40^{\circ} \mathrm{C}$ for $90 \mathrm{~min}$. The samples were then analysed by using GC-MS.

\section{GC-MS Analysis}

The operation parameter of GC-MS analysis was optimised as described by Azizan et al. (2015) with minor modifications. A Perkin Elmer Clarus 600 GCMS with auto sampler (quadrupole mass selective detector) on an electron ionisation (EI) operated at $70 \mathrm{eV}$ was used for the analysis. Samples $(1 \mu \mathrm{l})$ were injected into the Elite-5MS capillary column $(30 \mathrm{~m} \times 0.25 \mathrm{~mm}$ i.d. $\times 0.25 \mu \mathrm{m}$ thickness $)$ in a split mode (50:1) with an injection temperature at $250^{\circ} \mathrm{C}$ and ion source temperature at $300^{\circ} \mathrm{C}$. The helium gas flow was constantly set at $1 \mathrm{ml} \mathrm{min}^{-1}$ with oven temperature set from $70^{\circ} \mathrm{C}$ to $300^{\circ} \mathrm{C}$. The full scan mode was acquired at mass range of $m / z 45-600$.

\section{Data Processing}

Data analysis was carried out by using Turbo Mass software (Perkin Elmer, USA). Metabolites were identified by comparing MS spectra with the National Institute of Standards and Technology (NIST) library with cut off probability of $\geq 700$. Heat map was constructed by using MetaboAnalyst 3.0 software (Xia et al., 2016). All metabolites were normalised by the internal standard ribitol (100 ppm) and subjected to $\log 10$ transformation. Principal component analysis (PCA) was performed by exporting the normalised data into Soft Independent Modeling of Class Analogy (SIMCA)-P (version 11.0, Unimetrics $\mathrm{AB}$, Umea, Sweden) to identify metabolites that were differentiated in the sample treatments. The metabolites were classified using Pubchem database (Kim et al., 2016). Subsequently, two-way analysis of variance (ANOVA) using SPSS version 23 was performed to determine the significantly different metabolites towards different storage parameters. $P<0.05$ was considered statistically significant.

\section{RESULTS AND DISCUSSION}

\section{Effects of Storage Conditions, Durations and Temperatures on COPT Metabolites}

GC-MS and MVA were used to determine the metabolite changes in the COPT sap in response to different storage conditions, durations and temperatures. In total, 44 metabolites were identified and their relative concentrations were determined. By comparison, sugars and organic acids had the highest levels of relative concentration among the other identified metabolites (Table 1). The trends in metabolite concentrations have variously been attributed to environmental and analytical factors (Maier et al., 2010; Heuberger et al., 2014).

Table 1 shows the relative concentration of sugars such as glucose, glucopyranose, fructose, xylose, galactofuranose, galactose, mannose, arabinose and mannopyranose were identified in the samples. Sugars are important to OPT as they provide nutrient substrates and important roles as primary messengers in signal transduction (Rolland et al., 2002). The significant increment of those sugar concentrations were obviously depicted as the sap was stored for $1 \mathrm{~W}$ and $1 \mathrm{M}$, particularly in raw condition. From the findings, the highest concentrations of fructose $(78.11 \pm 3.23 \mathrm{mg}$ $\left.\mathrm{ml}^{-1}\right)$, glucose $\left(219.45 \pm 3.74 \mathrm{mg} \mathrm{ml}^{-1}\right)$ and galactose (77.12 $\pm 2.98 \mathrm{mg} \mathrm{ml}^{-1}$ ) were obtained in $\mathrm{R}-4-1 \mathrm{~W}$, R-10-1M and R-4-1W samples respectively. While in the sap storage conditions, the highest fructose $\left(12.99 \pm 0.85 \mathrm{mg} \mathrm{ml}^{-1}\right)$, glucose $\left(200.61 \pm 1.26 \mathrm{mg} \mathrm{ml}^{-1}\right)$ and galactose $\left(6.76 \pm 1.12 \mathrm{mg} \mathrm{ml}^{-1}\right)$ were determined in S-4-1M, S-10-1W and S-4-1W.

Hamid et al. (2010) found similar trend of sugar contents increment as the storage time increased due to the different species, cultivation and storage conditions. The increment of sugars in COPT sap may be attributed to plant carbohydrate storage which was instantly metabolised into sugars upon stresses (Lamade et al., 2016). Subsequently, the activation of plant carbohydrate metabolism resulted in free sugars accumulation as response to stress (Prawitwong et al., 2012; Hamid, 2016). Despite that, tautomerisation was also involved during storage as influenced by amino acid (Liu et al., 2014; Varanasi et al., 2016) such as serine, alanine, glutamic acid and aspartic acid (Kosugi et al., 2010).

Organic acids found in stored COPT include acetic acid, malic acid, oleic acid, lactic acid and ribonic acid. The organic acid levels were highly found at $4^{\circ} \mathrm{C}$ compared to $10^{\circ} \mathrm{C}$. Metabolites such as malic acid and ribonic acid were two organic acids found in C- 0 and similarly found in S- 4 and R-4. Similar levels were observed from $8.88 \pm 0.13$ to $8.25 \pm 0.22 \mathrm{mg}$ $\mathrm{ml}^{-1}$ for malic acid and from $0.35 \pm 0.03$ to $0.47 \pm 0.05$ $\mathrm{mg} \mathrm{ml}^{-1}$ for ribonic acid, particularly in S-4-1 $\mathrm{m}$. This is probably due to the lower temperatures which may well preserve the organic acids.

However, more organic acids were found with decreasing levels observed as storage temperature increased to $10^{\circ} \mathrm{C}$ indicating the effects of higher storage temperatures on the total content of organic acids. Generally, organic acids are among the fundamental metabolites which are important for plants because they are considered as transitory or stored forms of fixed carbon. Organic acid can either be converted into carbohydrates thus their decrement may contribute to the accumulation of sugars in COPT. Results suggest that organic acids 
TABLE 1. RELATIVE SUGAR AND ORGANIC ACIDS CONCENTRATION IN THE STORED CORE OIL PALM TRUNK (COPT) SAP ( $\left.\mathrm{mg} \mathrm{ml}^{-1}\right)$

\begin{tabular}{|c|c|c|c|c|c|c|c|}
\hline & & & \multirow[t]{2}{*}{ C-0 } & \multicolumn{2}{|c|}{$4^{\circ} \mathrm{C}$} & \multicolumn{2}{|c|}{$10^{\circ} \mathrm{C}$} \\
\hline & & & & $1 W$ & $1 \mathrm{M}$ & $1 W$ & $\mathbf{1 M}$ \\
\hline \multirow[t]{22}{*}{ Sugars } & Fructose & Sap & $12.31 \pm 1.49$ & $10.97 \pm 1.72$ & $12.99 \pm 0.85$ & $12.37 \pm 2.16$ & $8.30 \pm 0.69$ \\
\hline & & Raw & - & $78.11 \pm 3.23$ & $15.79 \pm 0.78$ & $19.53 \pm 1.78$ & $71.71 \pm 3.41$ \\
\hline & Glucose & Sap & $44.87 \pm 1.99$ & $41.57 \pm 1.52$ & $42.33 \pm 1.93$ & $200.61 \pm 1.26$ & $78.53 \pm 2.15$ \\
\hline & & Raw & - & $37.00 \pm 1.77$ & $63.00 \pm 2.17$ & $113.63 \pm 1.66$ & $219.45 \pm 3.74$ \\
\hline & Galactose & Sap & $1.07 \pm 0.07$ & $6.76 \pm 1.12$ & $0.09 \pm 0.02$ & $0.14 \pm 0.01$ & $0.45 \pm 0.17$ \\
\hline & & Raw & - & $77.12 \pm 2.98$ & $47.44 \pm 2.65$ & $0.68 \pm 0.03$ & $2.79 \pm 0.55$ \\
\hline & Glucopyranose & Sap & $13.92 \pm 0.90$ & $7.48 \pm 1.13$ & $0.10 \pm 0.06$ & $3.41 \pm 0.07$ & $5.05 \pm 0.34$ \\
\hline & & Raw & - & $4.12 \pm 2.83$ & $4.30 \pm 0.55$ & $9.04 \pm 0.06$ & $1.05 \pm 0.01$ \\
\hline & Xylose & Sap & $4.93 \pm 0.92$ & $4.03 \pm 0.36$ & $3.84 \pm 0.22$ & $4.20 \pm 0.22$ & $5.22 \pm 0.38$ \\
\hline & & Raw & - & $18.08 \pm 1.23$ & $4.30 \pm 0.21$ & $4.55 \pm 0.86$ & $20.89 \pm 0.18$ \\
\hline & Ribose & Sap & $0.12 \pm 0.04$ & $0.10 \pm 0.04$ & $0.30 \pm 0.06$ & $0.23 \pm 0.09$ & $0.14 \pm 0.01$ \\
\hline & & Raw & - & $0.50 \pm 0.04$ & $0.20 \pm 0.06$ & nd & $1.29 \pm 0.01$ \\
\hline & Ribopyranose & Sap & nd & $2.83 \pm 0.15$ & nd & nd & $1.85 \pm 0.12$ \\
\hline & & Raw & - & $4.50 \pm 1.19$ & $0.30 \pm 0.01$ & nd & nd \\
\hline & Mannose & Sap & $0.48 \pm 0.18$ & $0.27 \pm 0.13$ & $0.49 \pm 0.14$ & $0.06 \pm 0.01$ & $0.11 \pm 0.01$ \\
\hline & & Raw & - & $0.40 \pm 0.02$ & $1.30 \pm 0.05$ & $0.15 \pm 0.02$ & $0.16 \pm 0.01$ \\
\hline & Galactofuranose & Sap & $1.90 \pm 0.63$ & $1.26 \pm 0.23$ & $1.62 \pm 0.22$ & nd & nd \\
\hline & & Raw & - & $2.20 \pm 0.61$ & $1.60 \pm 0.21$ & nd & nd \\
\hline & Arabinose & Sap & nd & nd & nd & nd & nd \\
\hline & & Raw & - & nd & nd & $0.05 \pm 0.01$ & $0.07 \pm 0.02$ \\
\hline & Mannopyranose & Sap & nd & nd & nd & nd & nd \\
\hline & & Raw & - & nd & nd & $0.26 \pm 0.14$ & nd \\
\hline \multirow{10}{*}{$\begin{array}{l}\text { Organic } \\
\text { acids }\end{array}$} & Acetic Acid & Sap & nd & nd & nd & $0.12 \pm 0.05$ & $0.32 \pm 0.01$ \\
\hline & & Raw & nd & nd & nd & $0.09 \pm 0.00$ & \\
\hline & Malic Acid & Sap & $8.88 \pm 0.13$ & $7.14 \pm 0.10$ & $8.25 \pm 0.22$ & $1.03 \pm 0.08$ & nd \\
\hline & & Raw & - & $24.17 \pm 0.51$ & $10.96 \pm 0.52$ & $1.76 \pm 0.00$ & $2.54 \pm 0.62$ \\
\hline & Oleic Acid & Sap & nd & nd & nd & nd & $0.16 \pm 0.04$ \\
\hline & & Raw & - & nd & nd & $0.18 \pm 0.00$ & nd \\
\hline & Lactic Acid & Sap & nd & nd & nd & nd & nd \\
\hline & & Raw & - & nd & nd & nd & $0.086 \pm 0.00$ \\
\hline & Ribonic Acid & Sap & $0.35 \pm 0.03$ & $0.34 \pm 0.02$ & $0.47 \pm 0.05$ & nd & nd \\
\hline & & Raw & - & $0.60 \pm 0.43$ & $0.41 \pm 0.02$ & nd & nd \\
\hline
\end{tabular}

Note: nd - not detected. $1 \mathrm{~W}$ - one week. 1M - one month.

were higher and well preserved when they are stored at $4^{\circ} \mathrm{C}$ compared to $10^{\circ} \mathrm{C}$.

\section{Separation Pattern Analysis using PCA Score Plot and Loading Scatter Plot}

In order to evaluate the metabolite profiles of stored COPT sap, PCA was performed to further determine the response of different storage durations, conditions and temperatures. Interestingly, the separation patterns found in PCA score plot (Figure 1a) was greatest driven by storage temperatures rather by storage conditions and durations. Specifically, samples stored at $4^{\circ} \mathrm{C}$ (S-4-1W, S-4-1M, R-4-1W and R-4-1M) were closely clustered whereas samples stored at $10^{\circ} \mathrm{C}$ (S-10-1W, S-10-1M, R-10-1W and R-10-1M) were further separated along positive axis of principal component 1 (PC1).

Subsequently, loading scatter plot was performed to further identify metabolites with major contribution towards the separation pattern found in the PCA score plot. The loading plot in Figure $1 b$ suggested that discrimination of samples were contributed by a number of metabolites including glucose, arabinofuranose, galactopyranose and sulfurous acid. The dissipation trends of samples stored at $10^{\circ} \mathrm{C}$ along positive PC1 were contributed by metabolites of mannose and ribose for R-10-1W, glucopyranose for R-10-1M, xylose for S-10-1W and propanoic acid for $\mathrm{S}-10-1 \mathrm{M}$.

Differences in the relative concentration of metabolites are shown in the two-way hierarchical cluster analysis (HCA) and heat map (Figure 2). As shown in Figure 2, the heat map displays relative increase and/or decrease of metabolite levels. HCA dendrogram shows metabolite clustering between different storage conditions, durations and temperatures. Specifically, definitive differences in the relative concentration of metabolites can be observed between $4^{\circ} \mathrm{C}$ and $10^{\circ} \mathrm{C}$. The dendrogram also indicates two major clusters of metabolites. The upper cluster shows relatively high levels of metabolites, particularly glucose, fructose, ribose, 
(a)

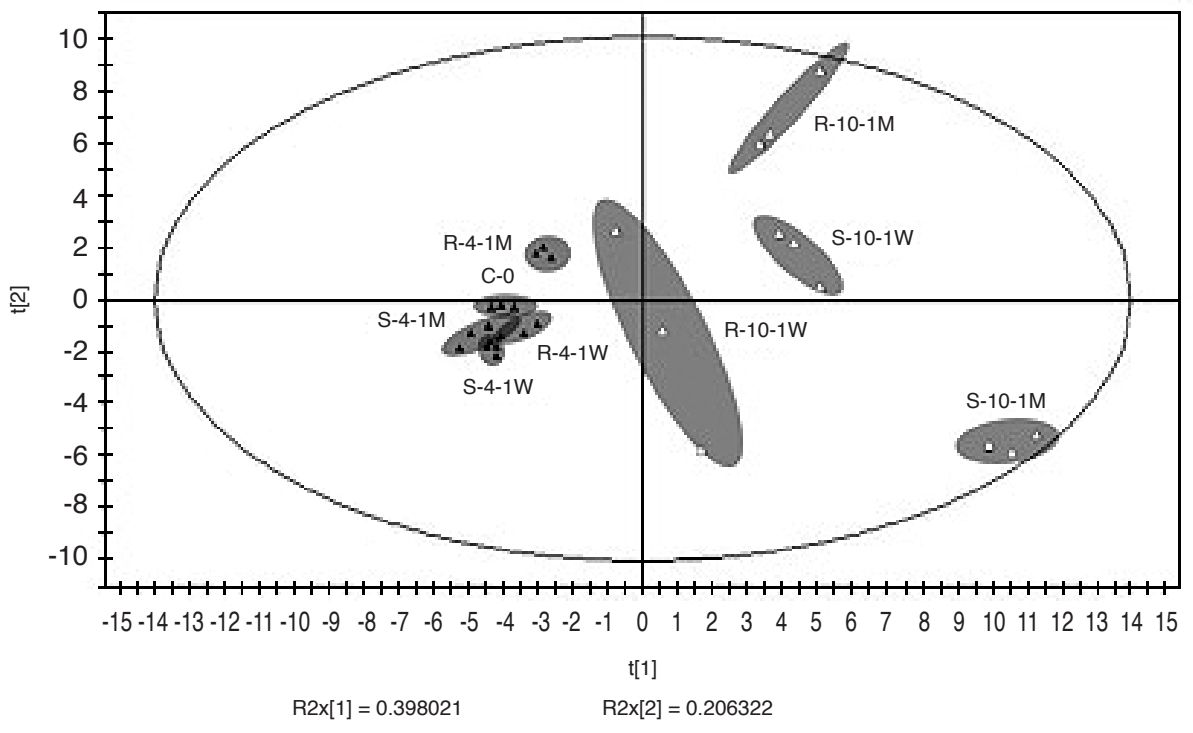

(b)

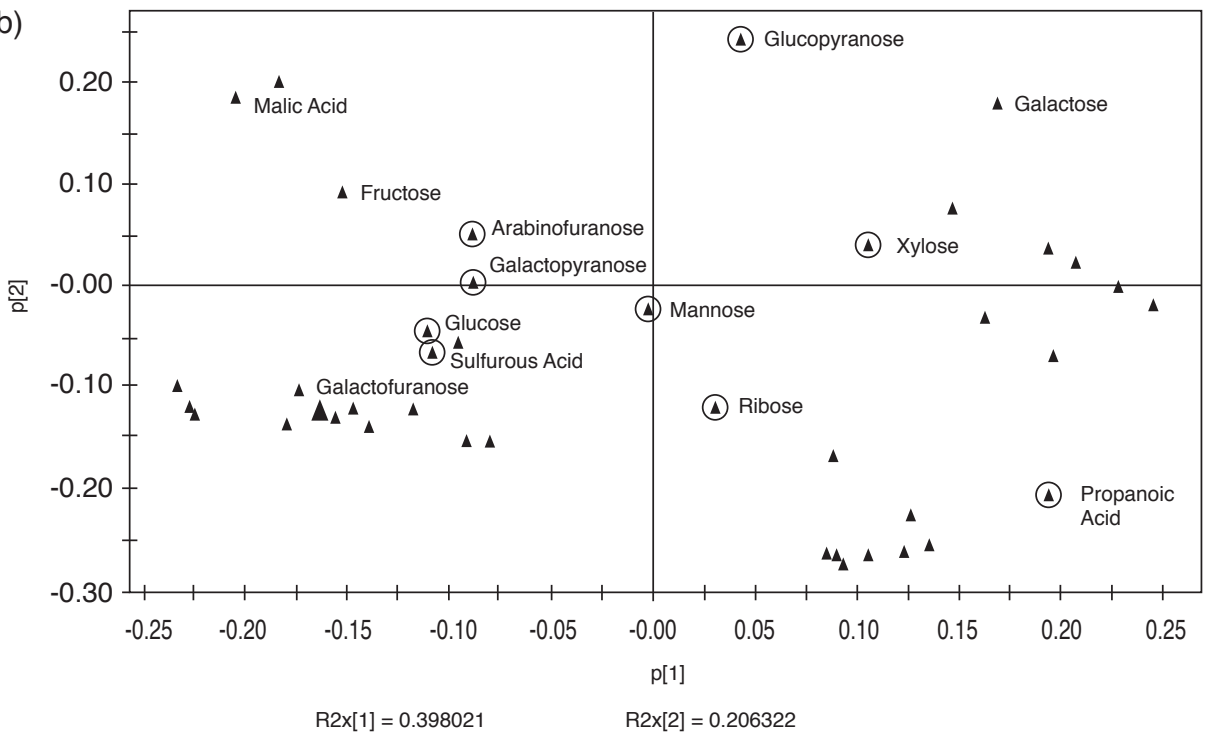

Figure 1. The general clustering patterns of stored core oil palm trunk (COPT) sap metabolites using principle component analysis (PCA): (a) PCA score plot of gas chromatography-mass spectrometry (GC-MS) based metabolites in COPT $\left(R^{2}=0.59 ; Q^{2}=0.367\right)$, (b) PCA loading plot of GC-MSbased metabolites in stored COPT sap $\left(R^{2}=0.59\right)$. The triangles labelled with circles were the metabolites that contributed towards the separation in PCA score plot.

mannose and organic acids of malic acid, lactic acid together with other sugar acids during the storage at $10^{\circ} \mathrm{C}$. Meanwhile, organic acids (such as acetic acid and oleic acid) and sugars (such as galactose and xylose) dominated the lower cluster of dendrogram during the storage at $4^{\circ} \mathrm{C}$.

Main and Interaction Effects Analysis of Different Storage Conditions, Durations and Temperatures Using Two-way ANOVA

The two-way ANOVA was used to determine the relationship and effect of the analytical factors on the sugars and organic acids that displayed significant difference (Table $2)$. The $P$-value showed that the majority of the metabolites were affected significantly by the storage durations. Sugars such as fructose, glucose and galactose showed higher significant differences $(P<0.001)$ under different storage durations. Malic, acetic and ribonic acids were affected significantly by storage durations and temperatures. Results indicated that sugars were mainly affected by the COPT storage conditions (sap or raw) and temperatures (Table 2). Organic acids were largely influenced by the COPT storage conditions and different storage durations.

\section{Miscellaneous Metabolites in COPT Sap}

A number of interesting metabolites were also detected in COPT sap with relatively low 


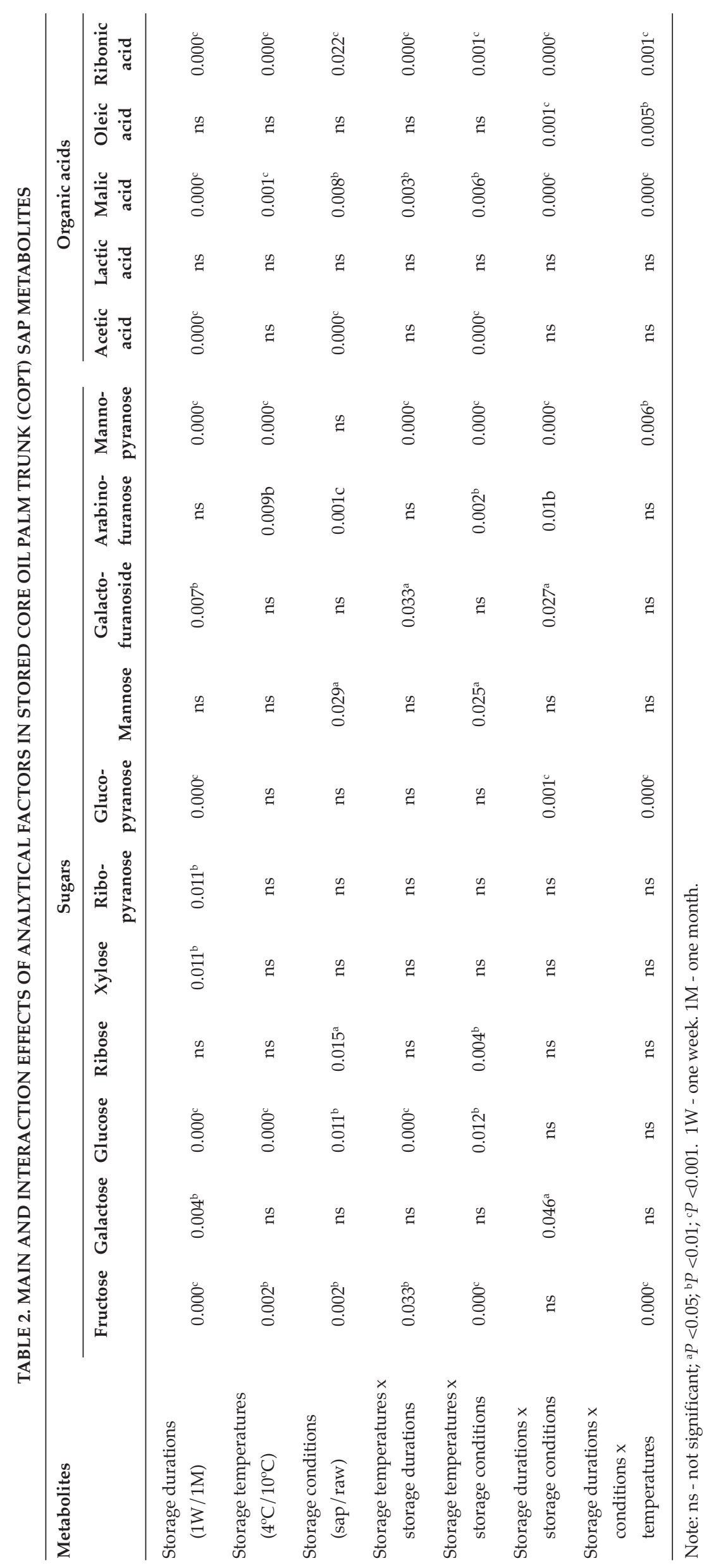


concentrations. These metabolites include compounds from the class of fatty acids (hexadecanoic acid and heptadecanoic acid), carboxylic acid (benzoic acid) and plant lipid (sitosterol, campesterol, stigmasterol and glycerol) which are generally found in plants as shown in Figure 2. In particular, lower lipids such as fatty acid was previously found in the OPT sap (1-5 wt $\%)$ as compared to other parts of oil palm such as mesocarp (20-60 wt\%) (Bourgis et al., 2011; Teh et al., 2013).

\section{CONCLUSION}

The dominant metabolites found in the COPT sap were sugars and organic acids. Highest sugars and organic acids concentration were found in R-10-1M sample. The results suggested that the sugar levels are highly influenced by all parameters; storage temperatures $\left(4^{\circ} \mathrm{C}\right.$ or $\left.10^{\circ} \mathrm{C}\right)$ durations $(1 \mathrm{~W} / 1 \mathrm{M})$ and storage conditions (sap or raw). However, the P-value showed that the majority of the metabolites

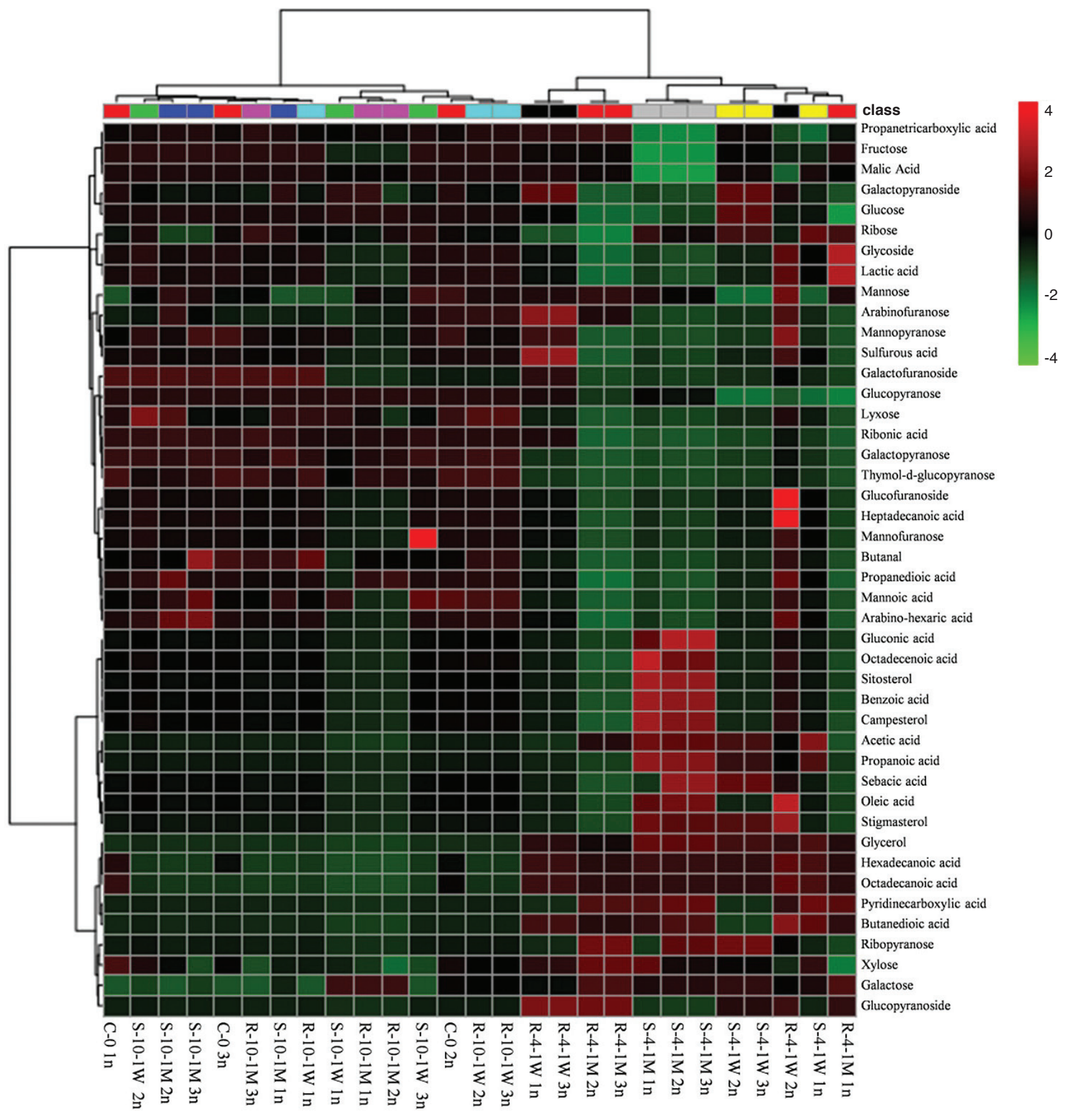

Figure 2. The heat map and hierarchal cluster dendrogram of stored core oil palm trunk (COPT) sap metabolites using hierarchical component analysis (HCA). 
were affected significantly by the storage durations. Sugars such as fructose, glucose and galactose showed higher significant differences $(P<0.001)$ under different storage durations.

\section{ACKNOWLEDGEMENT}

We would like to acknowledge the financial support through the ZF-2017-001 and Ministry of Higher Education Malaysia (MyBrain 15).

\section{REFERENCES}

ABDULLAH, N and SULAIMAN, F (2013). The oil palm wastes in Malaysia. Biomass Now-sustainable Growth and Use. InTech. DOI: 10.5772 / 55302.

AHMAD, Z; SAMAN, H M and TAHIR, P M (2010). Oil palm trunk fiber as a bio-waste resource for concrete reinforcement. International J. Mechanical and Materials Engineering, 5(2): 199-207.

AZIZAN, K A; HAIZUN, N; GHANI, A and NAWAWI, M F (2015). GC-MS based metabolomics and multivariate statistical analysis of Wedelia trilobata extracts for the identification of potential phytochemical properties. Plant Omics J., 8: 537-543.

BOURGIS, F; KILARU, A; CAO, X; NGANDOEBONGUE, G F; DRIRA, N; OHLROGGE, J B and ARONDEL, V (2011). Comparative transcriptome and metabolite analysis of oil palm and date palm mesocarp that differ dramatically in carbon partitioning. Proc. Natl. Acad. Sci., 108: 12527-12532. DOI: $10.1073 /$ pnas.1106502108.

CAO, H X; SUN, C X; SHAO, H B and LEI, X T (2011). Effects of low temperature and drought on the physiological and growth changes in oil palm seedlings. African J. Biotechnology, 10(14): 2630-2637.

CHARRIER, G; NGAO, J; SAUDREAU, $\mathrm{M}$ and AMÉGLIO, T (2015). Effects of environmental factors and management practices on microclimate, winter physiology, and frost resistance in trees. Front. Plant Sci., 6 (259): 1-18. DOI: 10.3389 / fpls.2015.00259.

CHOOKLIN, S; KAEWSICHAN, L and KAEWSRICHAN, J (2011). Potential utilization of sap from oil palm (Elaeis guineensis) for lactic acid production by lactobacillus casei. J. Sus. Ener. Environ., 2: 99-104.

FIELD, K J and LAKE, J A (2011). Environmental metabolomics links genotype to phenotype and predicts genotype abundance in wild plant populations. Physiol Plant., 142: 352-360. DOI: 10.1111/j.1399-3054. 2011.01480.x.
HAMID, Z A; SULAIMAN, O; HASHIM, R; ARAI, T; MORI, Y; TANAKA, R; KOSUGI, A; MURATA, Y and YAMAMOTO, K (2010). Preliminary study of oil palm trunk sap and starch content from various cultivars at different storage time. $4^{\text {th }}$ International Conference on Postgraduate Education.

HAMID, Z A (2016). Accumulation of Carbohydrate Reserve and its Composition in Oil Palm Trunk. Doctoral dissertation, Universiti Sains Malaysia.

HASHIM, R; WAN NADHARI, W N A; SULAIMAN, O; KAWAMURA, F; HIZIROGLU, S; SATO, M; TAY, G $S$ and TANAKA, R (2011). Characterization of raw materials and manufactured binderless particle board from oil palm biomass. Materials and Design, 32(1): 246-254

HEUBERGER, A L; BROECKLING, C D; KIRKPATRICK, K R and PRENNI, J E (2014). Application of non targeted metabolite profiling to discover novel markers of quality traits in an advanced population of malting barley. Plant Biotech. J., 12: 147-160. DOI: 10.1111/ pbi.12122.

JAHAR, N A; PUA, G; WONG, J C; MOSTAPHA, M; ZAKARIA, S; CHIA, C H and JAAFAR, S N S (2017). Utilization of core oil palm trunk waste to methyl levuinate: physical and chemical characterizations. Waste and Biomass Valorization. p. 1-6. DOI: 10.1007/ s12649-017-0085-9.

KOSUGI, A; TANAKA, R; MAGARA, K; MURATA, Y; ARAI, T; SULAIMAN, O; HASHIM, R; HAMID, Z A A; YAHYA, M K A; YUSOF, M N M; IBRAHIM, W A and MORI, Y (2010). Ethanol and lactic acid production using sap squeezed from old oil palm trunks felled for replanting. J. Bioscience and Bioengineering, 110(3): 322-325.DOI: https: / / doi.org /10.1016/j.jbiosc.2010.03.001.

KIM, S; THIESSEN, P A; BOLTON, E E; CHEN, J; FU, G; GINDULYTE, A; HAN, L; HE, J; HE, S; SHOEMAKER, B A; WANG, J; YU, B; ZHANG, $\mathrm{J}$ and BRYANT, S H (2016). PubChem substance and compound databases. Nucleic Acids Res., 44: D1202-D1213. DOI: 10.1093/nar/gkv 951.

LAMADE, E; TCHERKEZ, G; DARLAN, N H; RODRIGUES, R L; FRESNEAU, C; MAUVE, C and GHASHGHAIE, J (2016). Natural 13C distribution in oil palm (Elaeis guineensis Jacq.) and consequences for allocation pattern. Plant Cell Environ., 39: 199212. DOI:10.1111/ pce.12606.

LARCHER, W; KAINMUELLER, C and WAGNER, J (2010). Survival types of high mountain plants under extreme temperatures. Flora., 205: 3-18. DOI: 10.1016/j.flora.2008.12.005. 
LIU, C; CARRAHER, J M; SWEDBERG, J L; HERNDON, C R; FLEITMAN, C N and TESSONNIER, J P (2014). Selective base-catalyzed isomerization of glucose to fructose. ACS Catalysis. 4(12): 4295-4298. DOI: $10.1021 / \operatorname{cs501197w.~}$

MAIER, T S; KUHN, J and MÜLLER, C (2010). Proposal for field sampling of plants and processing in the lab for environmental metabolic fingerprinting. Plant Methods., 6: 1-5. DOI: 10.1186/1 746-4811-6-6.

MPOB (2016). Malaysia palm oil industry. http:/ / www.palmoilworld.org / about_malaysianindustry.html, accessed on 20 October 2016.

MPOC (2017). Monthly palm oil trade statistics November 2017. http://www.mpoc.org.my,/ accessed on 10 November 2017.

MOSTAPHA, M; JAHAR, N A; CHIN, S X; JAAFAR, S N S; ZAKARIA, S; AIZAT, W M and AZIZAN, K A (2016). Effect of zeolite catalyst on sugar dehydration for 5 hydroxymethylfurfural synthesis. American Institute of Physics Conference Proc., 1784(1): 040026. DOI: $10.1063 / 1.4966812$.

NEOH, B K; THE, H F; NG, T L M; TIONG, S H; THANG, YM;ERSAD, MA; MOHAMED, M; CHEW, F T; KULAVEERASINGAM, H and APPLETON, D R (2013). Profiling of metabolites in oil palm mesocarp at different stages of oil biosynthesis. J. Agric. Food Chem., 2: 1-8. DOI: 10.1021/jf304561f.

PRAWITWONG, P; KOSUGI, A; ARAI, T; DENG, L; LEE, K C; IBRAHIM, D; MURATA, Y; SULAIMAN, O; HASHIM, R;SUDESH, K; IBRAHIM, W A; SAITO, $\mathrm{M}$ and MORI, Y (2012). Efficient ethanol production from separated parenchyma and vascular bundle of oil palm trunk. Bioresource Technology, 125: 37-42. DOI: 10.1016/ j.biortech.2012.08.136.

ROLLAND, F; MOORE, B and SHEEN, J (2002). Sugar sensing and signaling in plants. The Plant Cell., 14 (Suppl 1): S185-S205. DOI:10.1105/ tpc.010455.

RUITZ-MATUTE, A I; HERNANDEZHERNANDEZ, O; RODRIGUEZ-SANCHEZ, S; SANZ, M L and MARTINEZ CASTRO, I (2011). Derivatization of carbohydrates for GC and GC-MS analyses. J. Chromatography B., 879: 1226-1240. DOI: 10.1016/j.jchromb.2010.11.013.

SULAIMAN, O; SALIM, $\mathrm{N}$; NORDIN, N A; HASHIM, R; IBRAHIM, $\mathrm{M}$ and SATO, M (2012). The potential of oil palm trunk biomass as an alternative source for compressed wood. BioRes. 7(2): 2688-2706.

TEH, H F; NEOH, B K; HONG, M P L; LOW, J Y S; NG, T L M; ITHNIN, N and KULAVEERASINGAM, H (2013). Differential metabolite profiles during fruit development in high yielding oil palm mesocarp. PloS One., 8: e61344. DOI: 10.1371/ journal.pone.0061344.

VARANASI, S; RAO, K; RELUE, P A and YUAN, D (2016). U.S. patent No. 9,528,104. Washington, DC: US patent and Trademark Office.

VARGAS, L H G; NETO, J C R; DE-AQUINO RIBEIRO, J A; RICCI-SILVA, M E; SOUZA, M T; RODRIGUES, C M; DE OLIVEIRA, A E and ABDELNUR, P V (2016). Metabolomics analysis of oil palm (Elaeis guineensis) leaf: evaluation of sample preparation steps using UHPLC-MS/MS. Metabolomics, 12: 153-160. DOI: 10.1007/s11306-016$1100-\mathrm{z}$

WARTH, B; PARICH, A; BUESCHL, C; SCHOEFBECK, D; NEUMANN, N K N; KLUGER, B; SCHUSTER, K; KRSKA, R; ADAM, G; LEMMENS, $M$ and SCHUHMACHER, R (2015). GC-MS based targeted metabolic profiling identifies changes in the wheat metabolome following deoxynivalenol treatment. Metabolomics, 11(3): 722-738. DOI: 10.1007 / s11306-014-0731-1.

XIA, J and WISHART, D S (2016). Using MetaboAnalyst 3.0 for comprehensive metabolomics data analysis. Current Protocols in Bioinformatics, 55: 14.10.1-14.10.91. DOI: 10.1002/ cpbi.11.

YAMADA, H; TANAKA, R; SULAIMAN, O; HASHIM, R; HAMID, Z A A; YAHYA, M K A; KOSUGI, A; ARAI, T; MURATA, Y; NIRASAWA, S; YAMAMOTO, K; OHARA, S; YUSOF, M N M; IBRAHIM, W A and MORI, Y (2010). Old oil palm trunk: A promising source of sugars for bioethanol production. Biomass Bioener., 34: 1608-1613. DOI: 10.1016/j.biombioe.2010.06.011. 
Appendix 1

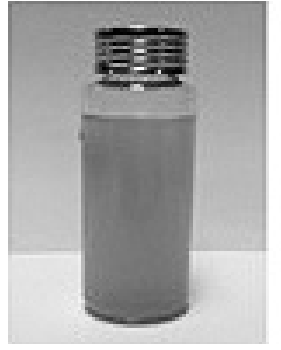

Sap

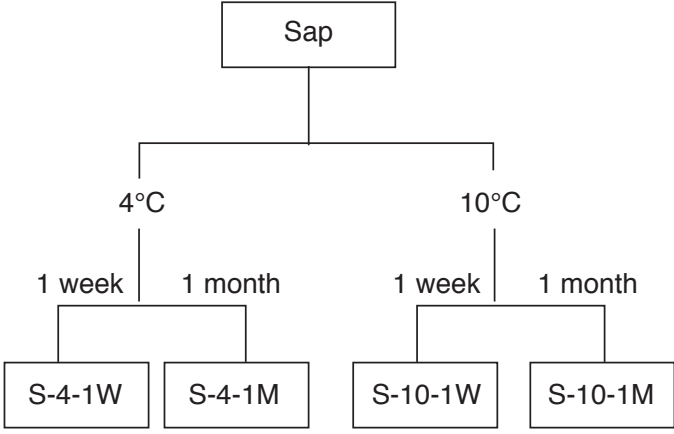

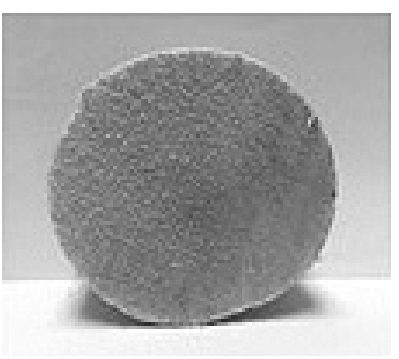

Raw

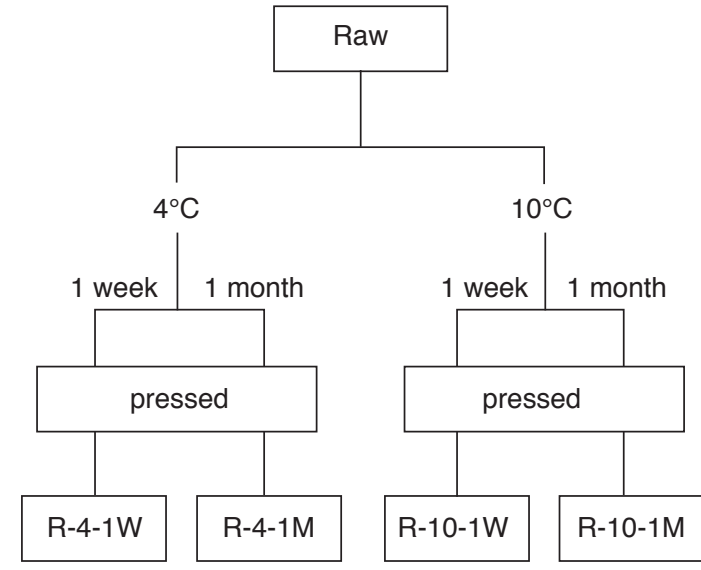

Work flow of samples preparation at different storage conditions (sap/raw), storage temperatures $\left(4^{\circ} \mathrm{C} / 10^{\circ} \mathrm{C}\right)$ and storage durations $(1$ week $/ 1$ month). 